\title{
BMJ Open Socioeconomic inequality in salt intake in Britain 10 years after a national salt reduction programme
}

\author{
Chen Ji, Francesco P Cappuccio
}

To cite: Ji C, Cappuccio FP. Socioeconomic inequality in salt intake in Britain 10 years after a national salt reduction programme. BMJ Open 2014:4:e005683.

doi:10.1136/bmjopen-2014005683

- Prepublication history and additional material is available. To view please visit the journal (http://dx.doi.org/ 10.1136/bmjopen-2014005683).

Received 12 May 2014 Revised 3 July 2014 Accepted 7 July 2014

CrossMark

Division of Mental Health \& Wellbeing, WHO

Collaborating Centre for Nutrition, Warwick Medical School, University of Warwick, Coventry, UK

\section{Correspondence to}

Professor Francesco $\mathrm{P}$

Cappuccio;

f.p.cappuccio@warwick.ac.uk

\section{ABSTRACT}

Objectives: The impact of the national salt reduction programme in the UK on social inequalities is unknown. We examined spatial and socioeconomic variations in salt intake in the 2008-2011 British National Diet and Nutrition Survey (NDNS) and compared them with those before the programme in 2000-2001.

Setting: Cross-sectional survey in Great Britain. Participants: 1027 Caucasian males and females, aged 19-64 years.

Primary outcome measures: Participants' dietary sodium intake measured with a 4-day food diary. Bayesian geo-additive models used to assess spatial and socioeconomic patterns of sodium intake accounting for sociodemographic, anthropometric and behavioural confounders.

Results: Dietary sodium intake varied significantly across socioeconomic groups, even when adjusting for geographical variations. There was higher dietary sodium intake in people with the lowest educational attainment (coefficient: 0.252 ( $90 \%$ credible intervals $0.003,0.486)$ ) and in low levels of occupation (coefficient: $0.109(-0.069,0.288))$. Those with no qualification had, on average, a $5.7 \%(0.1 \%, 11.1 \%)$ higher dietary sodium intake than the reference group. Compared to 2000-2001 the gradient of dietary sodium intake from south to north was attenuated after adjustments for confounders. Estimated dietary sodium consumption from food sources (not accounting for discretionary sources) was reduced by $366 \mathrm{mg}$ of sodium ( $\sim 0.9 \mathrm{~g}$ of salt) per day during the 10 -year period, likely the effect of national salt reduction initiatives.

Conclusions: Social inequalities in salt intake have not seen a reduction following the national salt reduction programme and still explain more than $5 \%$ of salt intake between more and less affluent groups. Understanding the socioeconomic pattern of salt intake is crucial to reduce inequalities. Efforts are needed to minimise the gap between socioeconomic groups for an equitable delivery of cardiovascular prevention.

\section{BACKGROUND}

High blood pressure (BP) is the most common, yet preventable, cause of morbidity,

\section{Strengths and limitations of this study}

- The National Diet and Nutrition Survey is a rolling programme of screening of a nationally representative sample of the British population regarding diet, nutrient intake and nutritional status.

- This analysis is the first evaluation of the effect of a national programme of salt reduction on social inequalities.

- The Bayesian approach allows for spatial variations as well as the contribution of known and unknown confounders to be determined.

- Estimates of dietary intake are reinforced by the parallel update of food composition tables on salt content.

- Dietary salt intake was assessed by 3-day or 4-day food diaries. This is at variance with the 2000-2001 survey when dietary salt intake was assessed with 7-day dietary records.

- Only salt coming from food was assessed, with no inclusion of discretionary salt deriving from that added to food at the table, and during the cooking process.

- The definitions of socioeconomic status were based on occupation and educational attainment.

- Results are based on the Caucasian respondents of the survey, since the representation of ethnic minority groups is still insufficient for independent analysis.

- Limitations are also due to the relatively small number of spatial units and regional classifications.

disability and death worldwide, responsible for more than half the deaths from coronary heart disease (CHD), stroke and cardiovascular disease (CVD). ${ }^{1}$ The risk of CVD is now becoming more prevalent in low-income and middle-income countries ${ }^{2}$ and, within countries, is more prevalent in socially disadvantaged groups. ${ }^{3}$ A reduction in high $\mathrm{BP}$ with antihypertensive medications significantly reduces $\mathrm{BP}$ and CVD. ${ }^{4}$ However, the majority of events in the population occur in the range of BP not qualifying for drug therapy. ${ }^{5}$ 
A population approach to achieve small BP reductions across the whole range of $\mathrm{BP}$ levels would therefore avert the majority of CVD events. ${ }^{6}$ Finally, in low-income and middle-income countries the implementation of healthcare programmes of detection, management and control of hypertension with drugs is still haphazard due to high costs and lack of healthcare infrastructures, ${ }^{7} 8$ making non-pharmacological public health programmes of primary prevention a cost-effective priority. ${ }^{9}{ }^{10}$

Evidence from a variety of sources shows a consistent relationship between salt intake and $\mathrm{BP}$, so that a moderate reduction in salt intake reduces $\mathrm{BP}$ in a dosedependent manner, in men and women, young and old, from all ethnic groups and at any level of $\mathrm{BP}^{11}$ Furthermore, there is evidence to suggest that these effects on BP could lead to a significant reduction in cardiovascular events, and crucially in strokes. $^{12}{ }^{13}$ Several approaches can be taken to reduce population salt intake ${ }^{11}$ and national and international organisations have now developed policies and started population programmes aiming at a reduction in population salt intake, ${ }^{14}$ a cost-effective prevention policy ${ }^{15} 16$ with rapidly occurring health benefits. ${ }^{17} 18$

Dietary salt, primarily sodium chloride, is commonly used for food preservation and seasoning. In most westernised countries, like the UK, approximately $75 \%$ of salt consumed is hidden in processed and restaurant foods whereas only about $15 \%$ comes from discretionary use (added at the table or in cooking by the consumer or food handler). ${ }^{19}$

Driven by this evidence, the UK Food Standards Agency (FSA) initiated a salt reduction programme in 2003 , aiming to reduce the average salt intake to $6 \mathrm{~g}$ /day in the UK population. ${ }^{20}$ Later, the FSA and the Department of Health worked together with the food industry to reduce the sodium content in processed foods by setting voluntary salt reduction targets, ran a public campaign to raise customer awareness and developed a food labelling scheme. ${ }^{21}$ After 10 years, salt intake in the UK has decreased by $1.4 \mathrm{~g} /$ day, a $15 \%$ reduction, from 9.5 to $8.1 \mathrm{~g} /$ day. $^{22}$ This reduction has been associated with a BP reduction of 3.0/1.4 $\mathrm{mm} \mathrm{Hg}$ and a parallel decline in CHD and stroke mortality. ${ }^{22}$ The sodium content of processed food in supermarkets has also been reduced by $20-30 \%,{ }^{23}$ particularly in packaged bread, the biggest contributor of salt intake in the British diet. ${ }^{24}$

Health inequalities are variations in health status across individuals in a population. ${ }^{25}$ Health inequalities by socioeconomic status (SES) are common. CVD is more prevalent in socioeconomically deprived populations and groups within populations. Low SES is associated with hypertension and high risks of stroke, CHD and renal failure. ${ }^{26}$ These groups are more likely to depend on cheaper unhealthy processed food diets, high in salt. ${ }^{27}$ The Marmot Review ${ }^{28}$ affirmed social inequalities as important determinants of ill-health in the British population, highlighting the social gradient in health inequalities, whereby people of poorer background not only die sooner but spend more of their lives with disabilities. There are different methods to measure inequalities in health. ${ }^{3} 252930$ Health inequalities arise from a complex interaction of many factors, one of which is poor diet and nutrition. Health inequalities are preventable through government policies aimed at the population as a whole. ${ }^{28}$ In general, 'downstream' preventive interventions with focus on individual behavioural changes are more likely to increase health inequalities than 'upstream' social or policy interventions. ${ }^{31}$ Among the former, media campaigns may be particularly likely to increase inequalities while the latter tend to reduce health inequalities, as they are usually 'structural' ${ }^{32}{ }^{33}$ Furthermore, the risk of hypertension associated with low parental social status can be modified by an improvement in social status later in life, ${ }^{34}$ suggesting effective targets for public health policies and political interventions. In a previous analysis using the National Diet and Nutrition Survey (NDNS) 2000-2001, we identified significant spatial and socioeconomic patterns of salt intake (measured by dietary sodium and urinary sodium) in Britain. ${ }^{35}$ In 2105 men and women aged 19-64 years, salt consumption was assessed using both 7-day dietary records and $24 \mathrm{~h}$ urinary sodium excretion. Socioeconomic position was defined both on head of household occupation and also on participant's educational attainment. Bayesian geo-additive models via Markov Chain Monte Carlo simulations were used to test the independent associations accounting for linear and non-linear effects and spatial variations. Dietary and total salt consumption were higher in Scotland and in lower socioeconomic groups, whether assessed by occupation or by educational attainment (with difference estimates varying from $4 \%$ to $9 \%$ ). As the UK programme has successfully reduced the population salt intake, it is yet unknown whether this national programme has made any change in this inequality. Thus, this paper aims to examine the spatial and socioeconomic patterns of salt intake using recently released UK NDNS data (2008-2011), and compare the possible change of these patterns before and after the implementation of the UK salt reduction programme.

\section{Data and methods}

This analysis was conducted using data from the 20082011 British NDNS. This survey is part of a national programme set up in 1992 to provide a cross-sectional and nationally representative sample of the British population regarding diet, nutrient intake and nutritional status. Details of the fieldwork and the survey are described elsewhere. ${ }^{36}$ In 2008, it changed to a Rolling Programme to better capture trends and to quickly meet political needs. One thousand to 1500 people aged 1.5-94 years are recruited every year as a representative sample of the general population in the UK (including England, Wales, Scotland and Northern Ireland). Participants are classified into three age groups: 1.5-18 years, 19-64 years and 
65 years and over. The fieldwork for the latest survey was carried out throughout 2008-2011 to account for any possible seasonal variations in dietary intake. At the household level, about $26 \%$ of the 9990 issued household addresses were selected for the survey in 3 years. On an individual level, 3073 people participated in the interview by completing a series of questionnaires and measurements, including a 3-day or 4-day food diary, a sociodemographic background interview, height and weight measurements, smoking and drinking assessments by selfcompleted questionnaires and an assessment of physical activity by self-completed questionnaires or ActiGraph. Seventy-five per cent (unweighted for age, $\mathrm{N}=2318$ ) of the participants were then visited by a nurse. This procedure included physical and BP measurements, a blood sample and $24 \mathrm{~h}$ urine collection, and collection of data on prescribed medicines. At this stage, $53 \%$ (unweighted for age, $\mathrm{N}=1614$ ) of the interviewed participants provided $24 \mathrm{~h}$ urine sample (data not released to date). Of the total participants, 39\% (N=1186) were adults (19-64 years). Caucasian respondents accounted for $90 \%(\mathrm{~N}=1069)$ of the adult population. Ethnic minority groups were excluded since estimation on few participants may not be representative of their ethnic group, particularly when compared by region. Finally, participants from Northern Ireland were also excluded due to small numbers $(n=42)$, leaving a total sample size of 1027.

Height and weight were measured to the nearest $0.1 \mathrm{~cm}$ and $0.1 \mathrm{~kg}$, respectively, to calculate body mass index $\left(\mathrm{BMI}=\right.$ weight/height $\left.\left(\mathrm{kg} / \mathrm{m}^{2}\right)\right)$. BP measurements were taken three times in a sitting position. The average of the second and third reading was used as the participant's BP level. SES was measured by two indicators, educational attainment and occupation. Educational attainment was based on the information of the highest qualification achieved. Some participants obtained foreign qualifications or were still in full-time education. Hence, a missing value was assigned to those participants. Occupation was determined by the socioeconomic classification (SEC) of the household reference person. Unlike the previous cross-sectional programme (based on The Registrar-General's Social Classes), the rolling programme defines the SEC by the National Statistics SEC (NS-SEC), ${ }^{37}$ which is developed from the Standard Occupational Classification 2010 (SOC2010). Details of the definitions of the classification can be found in the NDNS year 3 report. ${ }^{38}$ The NS-SEC grouped the participants into eight occupational classes: (1) higher managerial, administrative and professional; (2) Lower managerial, administrative and professional; (3) Intermediate; (4) Small employers and own account workers; (5) Lower supervisory and technical; (6) Semiroutine; (7) Routine; and (8) Never worked and long-term unemployed. The SES information was simplified into 3-class version ${ }^{39}$ : (1) Higher managerial, administrative and professional (containing level 1-2); (2) Intermediate (level 3-4); (3) Routine and manual (5-7). There were only 18 participants in the "Never worked and long-term unemployed' category (level 8). Hence, they were coded as missing values. Meanwhile, some participants classified as full-time students or other occupations not stated or inadequately described were also coded as missing values. Marital status included five categories: (1) single, (2) married and living with husband or wife, (3) married and separated, (4) divorced, (5) widowed. With the information of whether they were living with a partner, the marital status used in this analysis was coded as either living alone or living with partner. Smoking habit was derived from questions concerning smoking history. Based on their smoking history, the NDNS participants were recorded as current, former or non-smoker. Daily sodium intake was the outcome of interest. The food diary provided each participant's nutrient and energy intakes in weekdays and weekends. Sodium and energy intakes and alcohol consumption were based on the average of the 4-day dietary data. However, salt used in cooking and on the table (discretionary salt) was not measured.

\section{Geographical boundaries}

The NDNS rolling programme was conducted across the UK, including England, Scotland, Wales and Northern Ireland. ${ }^{40}$ The regional classification of England used in the rolling programme was different from the classification used in previous surveys, particularly in the north and south east part of England, which was mainly due to the use of Government Office Regions 2011. Details can be found on the website of the Office for National Statistics. ${ }^{41}$ As the Bayesian models are unable to make estimation over disconnected regions (ie, Northern Ireland and the rest of Great Britain), data collected from Northern Ireland were excluded from this study. Therefore, the analysis was limited to mainland Britain, and only boundary data of England, Scotland and Wales were collected from UKBORDERS.

\section{Statistical methods}

The Kruskal-Wallis test was used to compare the regional difference of dietary sodium intake. Bayesian geo-additive models were employed to analyse the spatial and socioeconomic patterns of sodium intake while accounting for the linear or non-linear effects of a range of important covariates, as detailed elsewhere. ${ }^{35}$ Four models were built and assessed. One level of each categorical factor was set as the reference level for effect assessment. Cube root transformation was used to normalise the dietary sodium intake. This was identical to the transformation used in our previous analysis. ${ }^{35}$ Deviance information criterion (DIC) was used for model selection. The model with the smallest DIC value was preferred (see online supplementary appendix 1). The descriptive analysis and tests were conducted using SPSS V.21 (IBM Corp., Armonk, New York, USA). Model estimations were conducted in BayesX V.2.1 (07.05.2012).$^{42}$ The statistical significance level was set as $\alpha=0.05$ in the descriptive analysis and $\alpha=0.1$ in the models. 


\section{RESULTS}

One thousand and twenty-seven Caucasian participants were included in the analysis. The age and sex adjusted characteristics of the study population are summarised in table 1. The mean age was 43.3 (95\% CI 42.5 to 44.0 ) years and women accounted for $56.4 \%(\mathrm{~N}=579)$ of the sample. $27.1 \%$ of the participants had a higher educational attainment, $31.1 \%$ an A level, below degree or equivalent educational attainment and $25.5 \%$ a General Certificate of Secondary Education (GCSE) or

Table 1 Age and sex adjusted characteristics of the population of the National Diet and Nutrition Survey 20082011

\begin{tabular}{|c|c|}
\hline Variable & Total $(\mathrm{N}=1027)$ \\
\hline Age (year) & 43.3 (42.5 to 44.0$)$ \\
\hline \multicolumn{2}{|l|}{ Sex $(\%)$} \\
\hline Male & 43.6 \\
\hline Female & 56.4 \\
\hline Weight (kg) & 78.9 (77.9 to 79.8$)$ \\
\hline Height (cm) & 169.5 (169.1 to 169.9$)$ \\
\hline BMI $\left(\mathrm{kg} / \mathrm{m}^{2}\right)$ & 27.4 (27.0 to 27.7$)$ \\
\hline \multicolumn{2}{|l|}{ Smoking habit (\%) } \\
\hline Non-smoker & 36.0 \\
\hline Former smoker & 36.6 \\
\hline Current smoker & 27.4 \\
\hline \multicolumn{2}{|l|}{ Marital status (\%) } \\
\hline Living with partner & 63.8 \\
\hline Living alone & 36.2 \\
\hline \multicolumn{2}{|l|}{ Education attainment (\%) } \\
\hline Higher education & 27.1 \\
\hline $\begin{array}{l}\text { Below degree, A level or } \\
\text { equivalent }\end{array}$ & 31.1 \\
\hline GCSE or equivalent & 25.5 \\
\hline No qualification & 16.2 \\
\hline \multicolumn{2}{|l|}{ Occupation (\%) } \\
\hline $\begin{array}{l}\text { Professional, managerial, } \\
\text { administrative }\end{array}$ & 45.9 \\
\hline Intermediate & 20.0 \\
\hline Routine and manual & 34.1 \\
\hline Sodium intake (mg/day) ${ }^{*}$ & 2245 (1092) \\
\hline Energy intake (kcal/day)* & $1799(761)$ \\
\hline Alcohol consumption (g/day) ${ }^{*}$ & $6.0(23.0)$ \\
\hline \multicolumn{2}{|l|}{ Region (\%) } \\
\hline North East & 4.2 \\
\hline North West & 13.0 \\
\hline Yorkshire and the Humber & 8.2 \\
\hline East Midlands & 10.7 \\
\hline West Midlands & 11.0 \\
\hline East of England & 9.7 \\
\hline London & 6.3 \\
\hline South East & 15.6 \\
\hline South West & 7.9 \\
\hline Wales & 5.9 \\
\hline Scotland & 7.5 \\
\hline \multicolumn{2}{|c|}{$\begin{array}{l}{ }^{*} \text { Median with IQR. } \\
\text { Results are mean ( } 95 \% \text { Cls) and percentage, unless stated. } \\
\text { BMI, body mass index; GCSE, General Certificate of Secondary } \\
\text { Education. }\end{array}$} \\
\hline
\end{tabular}

equivalent educational attainment. Participants in higher socioeconomic groups accounted for $45.9 \%$ of the sample.

\section{Dietary sodium}

The median sodium intake was $2245(\mathrm{IQR}=1092) \mathrm{mg} /$ day, which approximated to $5.6 \mathrm{~g}$ of salt/day $(100 \mathrm{mg}$ sodium $=0.25 \mathrm{~g}$ salt $)$. The median energy intake was 1799 $(\mathrm{IQR}=761) \mathrm{kcal} /$ day. Figure 1 shows the observatory map of sodium intake by region. Sodium intake was highest in Scotland, followed by the West Midlands. The regional differences, however, were not statistically significant ( $\mathrm{p}=0.145$; table 2 ).

The DIC results of the models were presented in online supplementary appendix 1 . Model 3 with linear assumption of the covariates performed the best in terms of the DIC value. Hence, the results of Model 3 were presented in table 3 . Once adjusted for all confounders in the model, dietary sodium intake significantly decreased with age and men had higher dietary sodium intake than women. As expected, dietary sodium intake was positively associated with body mass as a result of its association with energy intake. Participants at the lowest end of educational attainment (no qualification) had significantly higher dietary sodium intake than the reference group (higher education at degree level; 5.7\% $(0.1 \%, 11.1 \%)$; online supplementary appendix 2$)$. To avoid the effect of residual confounding, a set of models with five-category occupation was also examined. No substantial change, particularly in terms of the statistical significance, was detected between the two approaches (results not shown). A similar trend (though not statistically significant) was observed between dietary sodium intake and occupation.

\section{Comparison with the 2000-2001 NDNS}

Compared with the analysis of the NDNS 2000-2001, ${ }^{35}$ while the spatial differences in dietary sodium intake in NDNS 2008-2011 still followed the pattern of increasing levels from south to north (with Scotland showing the highest), the results were no longer statistically significant (figure 1 and table 2). Between the two surveys (almost 10 years apart) there was an average reduction in dietary sodium intake of $366 \mathrm{mg} /$ day (or $0.9 \mathrm{~g}$ of salt/ day). Crucially, the socioeconomic gradient remained (figure 2). If anything, the proportional gap appeared to widen (from $3.5 \%(0.1 \%, 7.2 \%)$ to $5.7 \%(0.1 \%$, $11.1 \%)$ ) between those with no qualification and the reference group (higher education at degree level; see online supplementary appendix 2).

\section{DISCUSSION}

Our analysis confirms a socioeconomic gradient in dietary salt intake in Britain in 2008-2011 independent of a geographic gradient. In addition, it shows for the first time that after 10 years of a national programme of population reduction in salt intake, social inequalities in salt 
Figure 1 Estimated posterior mean residual spatial regional effects of dietary sodium intake. The colour band represents the range of regional effect. Shades in red/green correspond to high/ low level of dietary sodium consumption.

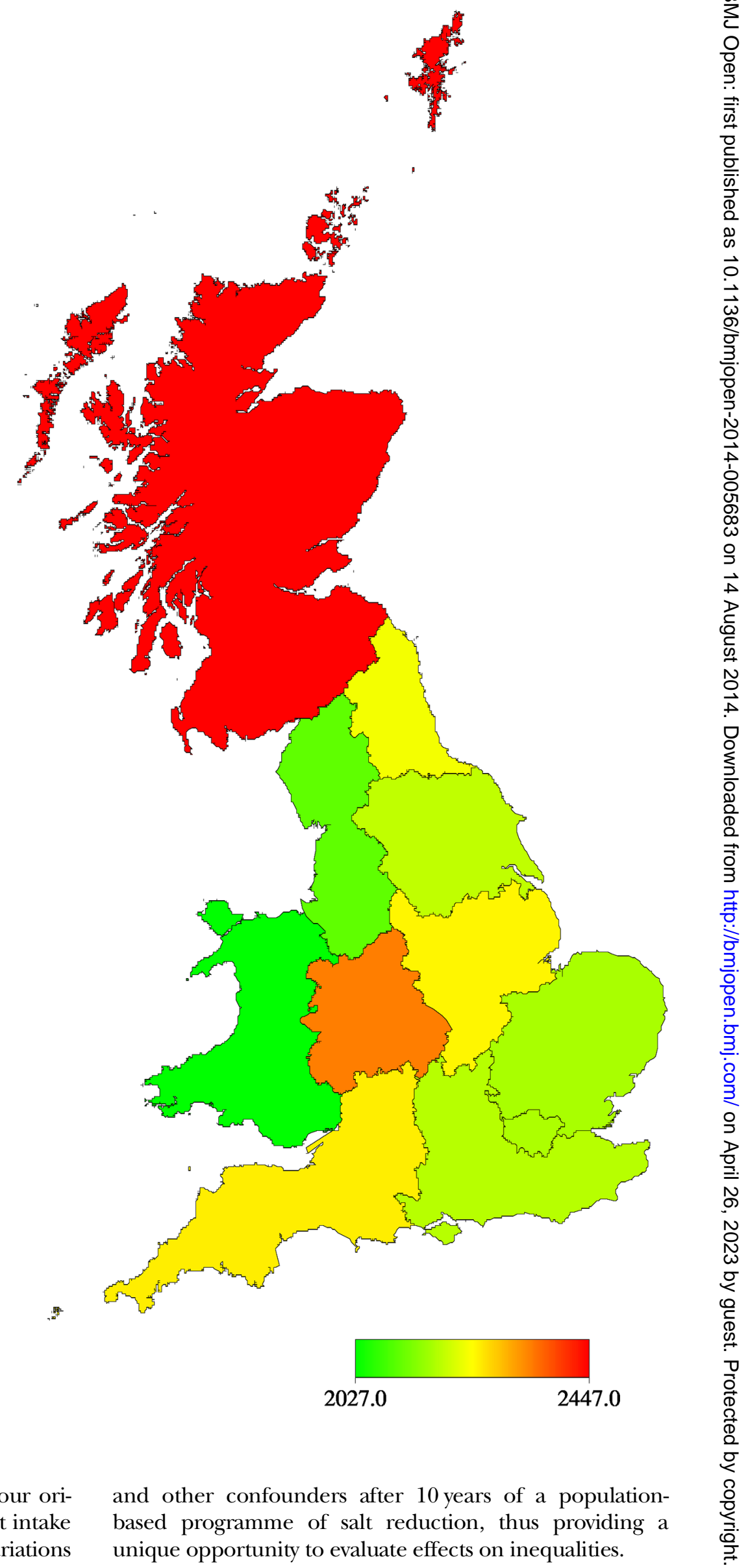

consumption have remained. This study extends our original approach of analysing spatial variations of salt intake to establish the contribution of socioeconomic variations based programme of salt reduction, thus providing a unique opportunity to evaluate effects on inequalities. 
Table 2 Dietary sodium intake (without discretionary salt consumption) by region in the 2008-2011 National Diet and Nutrition Survey sample of Caucasian participants

\begin{tabular}{lll}
\hline Region & $\begin{array}{l}\text { Sodium intake } \\
\text { (mg/day) } \\
\text { median (IQR) }\end{array}$ & $\begin{array}{l}\text { Salt equivalent } \\
\text { (g/day) } \\
\text { median (IQR) }\end{array}$ \\
\hline North East & $2106(1087)$ & $5.26(2.72)$ \\
North West & $2228(1104)$ & $5.57(2.76)$ \\
Yorkshire and the & $2186(1193)$ & $5.47(2.98)$ \\
Humber & & \\
East Midlands & $2244(1176)$ & $5.61(2.94)$ \\
West Midlands & $2343(1167)$ & $5.86(2.92)$ \\
East of England & $2167(1103)$ & $5.42(2.76)$ \\
London & $2170(1054)$ & $5.43(2.64)$ \\
South East & $2179(953)$ & $5.45(2.38)$ \\
South West & $2251(987)$ & $5.63(2.47)$ \\
Wales & $2027(1073)$ & $5.07(2.68)$ \\
Scotland & $2447(1046)$ & $6.12(2.62)$ \\
\hline
\end{tabular}

\section{Strengths and limitations}

The study has strengths. The NDNS is a rolling programme of screening of a nationally representative sample of the British population regarding diet, nutrient

Table 3 Fixed effect of dietary sodium intake in the 2008-2011 National Diet and Nutrition Survey sample of Caucasian participants

\begin{tabular}{|c|c|}
\hline Factor & $\begin{array}{l}\text { Mean } \\
\text { (90\% credible interval) }\end{array}$ \\
\hline Age (year) & $-0.012(-0.018,-0.006)$ \\
\hline Female & 0 \\
\hline Male & $0.342(0.176,0.499)$ \\
\hline BMI $\left(\mathrm{kg} / \mathrm{m}^{2}\right)$ & $0.018(0.003,0.032)$ \\
\hline \multicolumn{2}{|l|}{ Smoking habit } \\
\hline Non & 0 \\
\hline Former & $0.107(-0.048,0.264)$ \\
\hline Current & $-0.044(-0.241,0.152)$ \\
\hline \multicolumn{2}{|l|}{ Marital status } \\
\hline Living together & 0 \\
\hline Living alone & $0.005(-0.139,0.158)$ \\
\hline \multicolumn{2}{|l|}{ Education attainment } \\
\hline $\begin{array}{l}\text { Higher Education } \\
\text { (degree level) }\end{array}$ & 0 \\
\hline A level or equivalent & $0.191(0.009,0.380)$ \\
\hline GCSE or equivalent & $0.159(-0.060,0.367)$ \\
\hline No qualification & $0.252(0.003,0.486)$ \\
\hline \multicolumn{2}{|l|}{ Occupation } \\
\hline $\begin{array}{l}\text { Professional, managerial, } \\
\text { administrative }\end{array}$ & 0 \\
\hline Intermediate & $-0.036(-0.234,0.158)$ \\
\hline Routine and manual & $0.109(-0.069,0.288)$ \\
\hline Alcohol consumption (g/day) & $-0.009(-0.012,-0.006)$ \\
\hline Energy intake (kcal/day) & $0.0019(0.0018,0.002)$ \\
\hline \multicolumn{2}{|c|}{$\begin{array}{l}\text { Reference level was set as } 0 \text { in each categorical variable. } \\
\text { The effect is significant if the entire interval does not contain } 0 \\
\text { and it is printed in italics. } \\
\text { BMI, body mass index; GCSE, General Certificate of Secondary } \\
\text { Education. }\end{array}$} \\
\hline
\end{tabular}

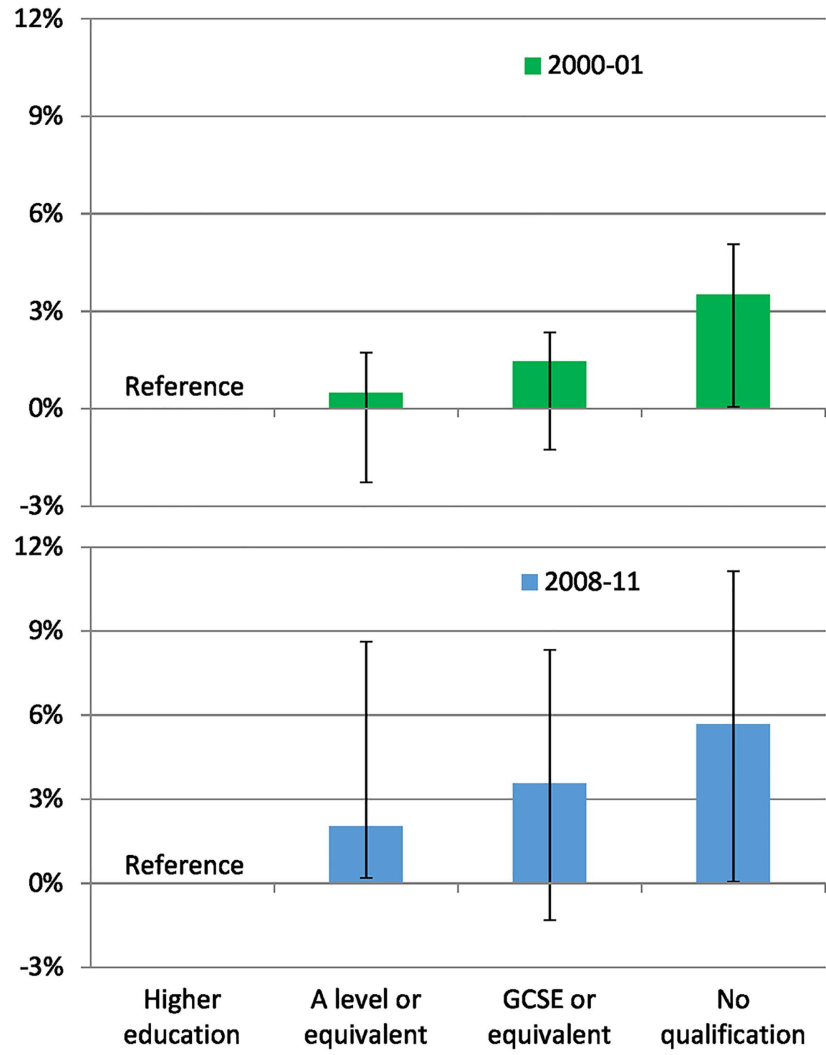

Figure 2 The effect of education attainment (and 90\% credible intervals) on dietary sodium intake in Britain in 20002001* (top) and 2008-2011 (bottom). Note: Higher education (degree level) was used as the reference level. The effect of each educational attainment was derived by assuming a $2500 \mathrm{mg}$ dietary sodium intake/day (approximately $6.26 \mathrm{~g} /$ day in salt, not including discretionary salt intake) for an adult holding a degree (reference). The effect is considered significant if the entire credible interval does not include 0 . *Although the Bayesian geo-additive models were used using the same set of factors with the same model setting, 'social class' was defined using a different classification in 2000-2001. In addition, the dietary sodium, energy and alcohol intakes were measured based on a 7-day dietary record in 2000-2001 and on 4-day food diaries in 2008-2011.

intake and nutritional status. This analysis is the first evaluation of the effect of a national programme of salt reduction on social inequalities. The Bayesian approach allows us to determine spatial variations as well as the contribution of known and unknown confounders. Finally, estimates of dietary intake are reinforced by the fact that food composition tables on salt content have been updated recently.

The study has limitations. Dietary salt intake was assessed by 3-day or 4-day food diaries. This is at variance with the 2000-2001 survey when dietary salt intake was assessed with 7-day dietary records. ${ }^{35}$ Notwithstanding the general comparability of group estimates using the two methods, ${ }^{43}$ in this round only salt coming from food was assessed, with no inclusion of discretionary salt deriving from that added to food at the table, and 
during the cooking process. Discretionary salt intake may account for approximately $15 \%$ of the total salt consumption, ${ }^{19}$ and additional socioeconomic inequalities in salt consumption may well depend on further variations in discretionary use. Total salt intake is best measured by $24 \mathrm{~h}$ urinary sodium excretion. ${ }^{45}{ }^{46}$ In the 2000-2001 analysis both spatial and socioeconomic patterns were comparable with dietary and total salt estimates. $^{35}$ The definitions of SES were based on occupation and educational attainment. While limited, these definitions are comparable to those used in 2000$2001{ }^{35}$ Our results are based on Caucasian respondents, since the representation of ethnic minority groups was still insufficient for an independent analysis. The generalisability of the findings is therefore limited to Caucasians. Limitations are also the relatively small number of spatial units and regional classifications. ${ }^{35}$ The possibility of residual confounding cannot be ruled out completely.

\section{Context}

The UK initiated a nationwide salt reduction programme in 2003/2004 based on several public awareness campaigns, setting progressing targets on the salt content of processed food led by the FSA, a voluntary agreement with the food industry to reformulate bread and processed foods and a rolling programme of repeated surveys to monitor the salt intake of the population ${ }^{11}$ and the salt content of some food categories. ${ }^{24}$ The programme has been successful and resulted in a $1.4 \mathrm{~g} /$ day (15\%) reduction in salt consumption in the English population by 2011, as measured by $24 \mathrm{~h}$ urinary sodium excretion (from $9.5 \mathrm{~g} /$ day in 2003 to $8.1 \mathrm{~g} /$ day in 2011). ${ }^{22}$ During the same period of time population BP fell by $3.0 / 1.4 \mathrm{~mm} \mathrm{Hg}(2.7 / 1.1 \mathrm{~mm} \mathrm{Hg}$ in those not on treatment for hypertension) and both stroke and IHD mortality decreased by $36 \% .^{22}$ The average salt level in bread fell from $1.23 \mathrm{~g} / 100 \mathrm{~g}$ in 2001 to $0.98 \mathrm{~g} / 100 \mathrm{~g}$ in 2011, and the number of products meeting the 2012 targets increased from $28 \%$ in 2001 to $71 \%$ in $2011 .{ }^{24}$ Our study indicates a $0.9 \mathrm{~g} /$ day reduction in population dietary salt intake between surveys, which should be interpreted as primarily deriving from food reformulation rather than by behavioural modifications in the use of discretionary salt at the table and in cooking.

\section{Implications for policy}

The diet of socioeconomically disadvantaged groups is made up of low-quality, salt-dense, high-fat, high-calorie unhealthy cheap foods. ${ }^{3}{ }^{47-53}$ A behavioural approach to healthy eating is unlikely to bring about the changes necessary to halt and reverse the non-communicable diseases epidemic and it may widen inequalities. ${ }^{11} 3254$ SES inequalities in dietary access and consumption of healthy foods are widely documented ${ }^{28}$ both within countries $^{3}$ and between countries, ${ }^{55}$ and for salt intake are detectable in children $^{56}$ as well as adults. ${ }^{35}$ Australian children from a low SES have on average 9\% greater intake of salt from food sources compared to those from a high SES. ${ }^{56}$ In our study these differences are estimated to be between $5 \%$ and $6 \%$.

The findings of a sustained SES gradient in population dietary salt intake from 2000-2001 to 2008-2011 is disappointing, as one would have expected a larger reduction in lower SES following a population-wide approach. ${ }^{32}$ There are multiple interpretations of these findings. First, our results do not indicate that the total salt consumption is still higher in low SES as we do not have measures of $24 \mathrm{~h}$ urinary sodium excretion in the 2008-2011 survey that are directly comparable with those taken in 20002001. However, in the 2000-2001 survey both measures (dietary sodium and $24 \mathrm{~h}$ urinary sodium) were used and the results were consistent. ${ }^{35}$ Second, to counterbalance the higher dietary salt intake in low SES, the same groups should have reduced discretionary salt substantially following public awareness campaigns, an effect not anticipated $^{32}$ and not reported as yet in the literature. Third, the inequalities we detect for dietary salt intake could be even greater if we assumed that the consumption of junk food from unregulated street retailers is more common in people of low SES. Indeed, recent results from the analysis of data for take-home food and beverage purchases from British households in 2010 indicates that shopping baskets of higher SES groups are healthier (proportionally more purchasing of fibre, protein and total sugars and less sodium) than those of lower SES groups. ${ }^{27}$ Fourth, it is possible that the reformulation of food items (beyond bread) has covered, disproportionately, food items not predominantly purchased by low SES groups. A more detailed monitoring of household food purchasing in relation to targeted reformulation and improved access by acting on pricing should be included in surveillance methods to reveal potential targets to reduce social inequalities in salt intake. Fifth, the UK salt reduction programme started with three waves of media campaigns to increase awareness and change behaviour. The engagement with industry, which included target settings and food reformulation, was implemented later and its effects might not have had enough time to impact on social inequalities.

\section{Conclusions}

Social inequalities in salt intake have not seen a reduction following the national salt reduction programme and still explain more than $5 \%$ of salt intake between more and less affluent groups. Understanding the socioeconomic pattern of salt intake is crucial to reduce inequalities. Efforts are needed to minimise the gap between socioeconomic groups for an equitable delivery of cardiovascular prevention.

Acknowledgements The analysis was carried out under the Terms of Reference of the WHO Collaborating Centre for Nutrition (UKN-219).

Contributors FPC developed the idea, obtained funding, supervised the analysis and drafted the manuscript. CJ carried out the statistical analysis and prepared the draft methods and results. FPC acts as guarantor.

Funding The Bupa Foundation (MR-12-002). 
Competing interests FPC is an unpaid member of CASH, WASH, UK National Forum, UK Public Health NACD; unpaid technical advisor to NICE, the WHO and the Pan-American Health Organization; and Trustee of the Student Heart Health charity.

\section{Ethics approval West Midlands BREC (158-01-2012).}

Provenance and peer review Not commissioned; externally peer reviewed.

Data sharing statement No additional data are available.

Open Access This is an Open Access article distributed in accordance with the Creative Commons Attribution Non Commercial (CC BY-NC 4.0) license, which permits others to distribute, remix, adapt, build upon this work noncommercially, and license their derivative works on different terms, provided the original work is properly cited and the use is non-commercial. See: http:// creativecommons.org/licenses/by-nc/4.0/

\section{REFERENCES}

1. Lozano R, Naghavi M, Foreman K, et al. Global and regional mortality from 235 causes of death for 20 age groups in 1990 and 2010: a systematic analysis for the Global Burden of Disease Study 2010. Lancet 2012;380:2095-128.

2. Gaziano TA. Cardiovascular disease in the developing world and its cost-effective management. Circulation 2005;112:3547-53.

3. Mackenbach JP, Stirbu I, Roskam AJ, et al. Socioeconomic inequalities in health in 22 European countries. $N$ Engl J Med 2008;358:2468-81.

4. Blood Pressure Lowering Treatment Trialists' Collaboration. Effects of ACE inhibitors, calcium antagonists, and other blood-pressure-lowering drugs: results of prospectively designed overviews of randomised trials. Lancet 2000;356:1955-64.

5. Lewington S, Clarke R, Qizilbash N, et al. Age-specific relevance of usual blood pressure to vascular mortality: a meta-analysis of individual data for one million adults in 61 prospective studies. Lancet 2002;360:1903-13.

6. Rose G. Sick individuals and sick populations. Int J Epidemiol 1985; 14:32-8

7. Joshi $\mathrm{R}$, Jan $\mathrm{S}, \mathrm{Wu} \mathrm{Y}$, et al. Global inequalities in access to cardiovascular health care: our greatest challenge. J Am Coll Cardiol 2008;52:1817-25.

8. Modesti PA, Agostoni P, Agyemang C, et al. Cardiovascular risk assessment in low-resource settings: a consensus document of the European Society of Hypertension Working Group on Hypertension and Cardiovascular Risk in Low Resource Settings. J Hypertens 2014;32:951-60.

9. Cooper RS, Kennelly JF, Ordunez-Garcia P. Health in Cuba. Int J Epidemiol 2006;35:817-24

10. Beaglehole R, Bonita R, Horton R, et al. Priority actions for the non-communicable disease crisis. Lancet 2011;377:1438-47.

11. Cappuccio FP, Capewell S, Lincoln P, et al. Policy options to reduce population salt intake. BMJ 2011;343:402-5.

12. Strazzullo P, D'Elia L, Kandala NB, et al. Salt intake, stroke, and cardiovascular disease: meta-analysis of prospective studies. BMJ 2009;339:b4567.

13. Aburto NJ, Ziolkovska A, Hooper L, et al. Effect of lower sodium intake on health: systematic review and meta-analyses. $B M J$ 2013;346:f1326.

14. Webster JL, Dunford EK, Hawkes C, et al. Salt reduction initiatives around the world. J Hypertens 2011;29:1043-50.

15. Murray CJ, Lauer JA, Hutubessy RC, et al. Effectiveness and costs of interventions to lower systolic blood pressure and cholesterol: a global and regional analysis on reduction of cardiovascular-disease risk. Lancet 2003;361:717-25.

16. Asaria $P$, Chisholm D, Mathers $C$, et al. Chronic disease prevention: health effects and financial costs of strategies to reduce salt intake and control tobacco use. Lancet 2007;370:2044-53.

17. Capewell S, O'Flaherty M. Can dietary changes rapidly decrease cardiovascular mortality rates? Eur Heart J 2011;32:1187-9.

18. Capewell S, O'Flaherty M. Rapid mortality falls after risk-factor changes in populations. Lancet 2011;378:752-3.

19. Mattes RD, Donnelly D. Relative contributions of dietary sodium sources. J Am Coll Nutr 1991;10:383-93.

20. He FJ, MacGregor GA. Reducing population salt intake worldwide: from evidence to implementation. Prog Cardiovasc Dis 2010;52:363-82.

21. Sadler K, Nicholson S, Steer T, et al. National Diet and Nutrition Survey. Assessment of dietary sodium in adults (aged 19-64) in England, 2011. Department of Health of England, 2014.
22. He FJ, Pombo-Rodrigues S, MacGregor GA. Salt reduction in England from 2003 to 2011: its relationship to blood pressure, stroke and ischaemic heart disease mortality. BMJ Open 2014;4:e004549.

23. He FJ, MacGregor GA. A comprehensive review on salt and health and current experience of worldwide salt reduction programmes. J Hum Hypertens 2009;23:363-84.

24. Brinsden $\mathrm{HC}, \mathrm{He} \mathrm{FJ}$, Jenner $\mathrm{KH}$, et al. Surveys of the salt content in UK bread: progress made and further reductions possible. BMJ Open 2013;3:e002936.

25. Gakidou EE, Murray CJ, Frenk J. Defining and measuring health inequality: an approach based on the distribution of health expectancy. Bull World Health Organ 2000;78:42-54

26. Colhoun HM, Hemingway H, Poulter NR. Socio-economic status and blood pressure: an overview analysis. J Hum Hypertens 1998;12:91-110.

27. Pechey R, Jebb SA, Kelly MP, et al. Socioeconomic differences in purchases of more vs. less healthy foods and beverages: analysis of over 25,000 British households in 2010. Soc Sci Med 2013;92:22-6.

28. Fair Society, Healthy Lives. The Marmot Review. Strategic Review of Health Inequalities in England post-2010. 2010:1-238. The Marmot Review.

29. ScotPHO. Measuring socio-economic inequalities in health: a practical guide. ScotPHO, 2007:1-7.

30. Mackenbach JP, Kunst AE. Measuring the magnitude of socio-economic inequalities in health: an overview of available measures illustrated with two examples from Europe. Soc Sci Med 1997;44:757-71.

31. Lorenc T, Petticrew M, Welch V, et al. What types of interventions generate inequalities? Evidence from systematic reviews. $J$ Epidemiol Community Health 2013;67:190-3.

32. Capewell S, Graham H. Will cardiovascular disease prevention widen health inequalities? PLoS Med 2010;7:e1000320.

33. Benach J, Malmusi D, Yasui Y, et al. A new typology of policies to tackle health inequalities and scenarios of impact based on Rose's population approach. $J$ Epidemiol Community Health 2013;67:286-91.

34. Barton $P$, Andronis L, Briggs A, et al. Effectiveness and cost effectiveness of cardiovascular disease prevention in whole populations: modelling study. BMJ 2011;343:d4044.

35. Ji C, Kandala NB, Cappuccio FP. Spatial variation of salt intake in Britain and association with socioeconomic status. BMJ Open 2013;3:e002246.

36. Hoare J, Henderson L, Bates CJ, et al. The National Diet and Nutrition Survey: adults Aged 19-64 years. 5: summary report. London: HMSO, 2004.

37. Rose D, Pevalin DJ. The National Statistics Socio-economic Classification: origins, development and use. Basingstoke: Palgrave Macmillan, 2005:1-120.

38. Bates B, Lennox A, Prentice A, et al. National Diet and Nutrition Survey. Headlines results from year 1,2 and 3 (combined) of the Rolling Programme (2008/2009-2010/11). Department of Health and Food Standard Agency, 2013.

39. ONS. http://www.ons.gov.uk/ons/guide-method/classifications/ current-standard-classifications/soc2010/soc2010-volume-3-ns-sec-rebased-on-soc2010--user-manual/index.htm

40. MRC. http://www.mrc-hnr.cam.ac.uk/research/current-projects/ national-diet-and-nutrition-survey

41. ONS. http://www.ons.gov.uk/ons/guide-method/geography/ beginner-s-guide/administrative/england/government-office-regions/ index htm

42. Brezger A, Kneib T, Lang S. et al. Software for Bayesan inference based on Markov Chain Monte Carlo simulation techniques. J Statist Software 2005;14:11.

43. Bingham SA, Gill C, Welch A, et al. Comparison of dietary assessment methods in nutritional epidemiology: weighed records v. $24 \mathrm{~h}$ recalls, food-frequency questionnaires and estimated-diet records. Br J Nutr 1994;72:619-43.

44. Lentjes MA, McTaggart A, Mulligan AA, et al. Dietary intake measurement using $7 \mathrm{~d}$ diet diaries in British men and women in the European Prospective Investigation into Cancer-Norfolk study: a focus on methodological issues. Br J Nutr 2014;111:516-26.

45. Ji C, Sykes L, Paul C, et al. Systematic review of studies comparing 24-hour and spot urine collections for estimating population salt intake. Rev Panam Salud Publica 2012;32:307-15.

46. Ji C, Miller MA, Venezia A, et al. Comparisons of spot vs 24-h urine samples for estimating population salt intake: validation study in two independent samples of adults in Britain and Italy. Nutr Metab Cardiovasc Dis 2014;24:140-7.

47. Rao M, Afshin A, Singh $\mathrm{G}$, et al. Do healthier foods and diet patterns cost more than less healthy options? A systematic review and meta-analysis. BMJ Open 2013;3:e004277. 
48. Banks J, Marmot M, Oldfield Z, et al. Disease and disadvantage in the United States and in England. JAMA 2006;295:2037-45.

49. Kant AK, Graubard BI. Secular trends in the association of socio-economic position with self-reported dietary attributes and biomarkers in the US population: National Health and Nutrition Examination Survey (NHANES) 1971-1975 to NHANES 19992002. Public Health Nutr 2007;10:158-67.

50. Darmon N, Drewnowski A. Does social class predict diet quality? Am J Clin Nutr 2008;87:1107-17.

51. Jetter KM, Cassady DL. The availability and cost of healthier food alternatives. Am J Prev Med 2006;30:38-44.

52. McDermott AJ, Stephens MB. Cost of eating: whole foods versus convenience foods in a low-income model. Fam Med 2010;42:280-4.
53. Rehm CD, Monsivais $\mathrm{P}$, Drewnowski $\mathrm{A}$. The quality and monetary value of diets consumed by adults in the United States. Am J Clin Nutr 2011;94:1333-9.

54. Hogberg L, Cnattingius S, Lundholm C, et al. Intergenerational social mobility and the risk of hypertension. $J$ Epidemiol Community Health 2012;66:e9.

55. Rodriguez-Fernandez R, Siopa M, Simpson SJ, et al. Current salt reduction policies across gradients of inequality-adjusted human development in the WHO European region: minding the gaps. Public Health Nutr 2014;17:1894-904.

56. Grimes CA, Campbell KJ, Riddell LJ, et al. Is socioeconomic status associated with dietary sodium intake in Australian children? A cross-sectional study. BMJ Open 2013;3:e002106. 


\section{Correction}

Ji C, Cappuccio FP. Socioeconomic inequality in salt intake in Britain 10 years after a national salt reduction programme. BMJ Open 2014;4:e005683. The authors have become aware that during the submission process the incorrect figure 2 was uploaded and subsequently published. The figure does not match the data reported in table 3 , which is indeed correct and it is referred to for the results of the study and discussion. Whilst the mistake is uninfluential, the figure may be misleading for some. The amended figure is below. The legend is unaffected.
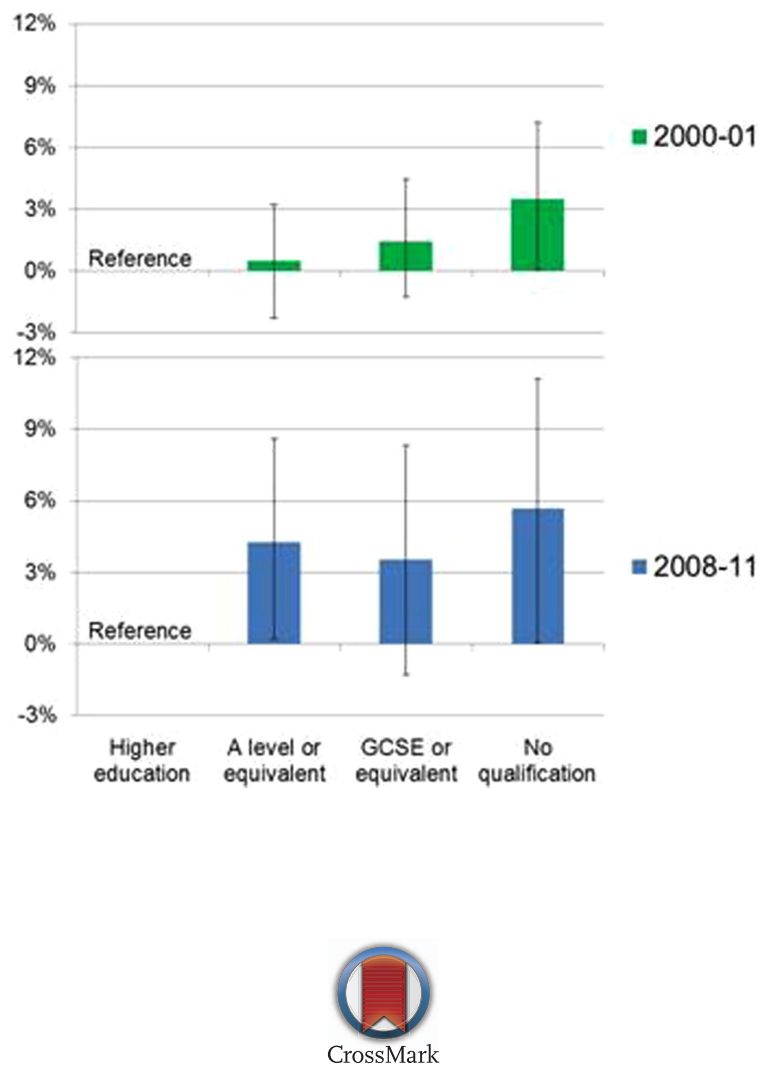

BMJ Open 2014;4:e05683corr1. doi:10.1136/bmjopen-2014-005683corr1 